\title{
THERMOPLASTIC APPLICATIONS FOR PULSE POWER ALTERNATORS
}

By:

C.S. Hearn

J.J. Hahne

H-P. Liu

M.D. Werst

13th Electromagnetic Launch Technology Symposium, Potsdam (Berlin), Germany, May 22-25, 2006

IEEE Transactions on Magnetics, vol. 43, no. 1, January 2007, pp. 238-241

PR 417

Center for Electromechanics

The University of Texas at Austin

PRC, Mail Code R7000

Austin, TX 78712

(512) 471-4496 


\title{
Thermoplastic Applications for Pulse Power Alternators
}

\author{
Clay S. Hearn, Jonathan J. Hahne, Hsing-Pang Lui, and Michael D. Werst \\ Center for Electromechanics at The University of Texas at Austin
}

\begin{abstract}
The field coil is the primary component of the rotor assembly that provides the rotating magnetic field for the pulse power alternator. The design of the field coil is optimized so that it will produce the required magnetic field with minimum transient losses. The high currents required to produce the correct amp-turns, along with the mechanical loads due to high rotational speeds, present further design requirements for selection of field coil material, insulation, and surrounding material that completes the matrix of the field coil subassembly. With the addition of active cooling requirements in the field coil design, surrounding materials must be selected that retain electrically insulative properties and are thermally conductive to allow sufficient heat removal from the field coil.

Thermoplastics are now being reviewed to replace traditional glass-epoxy potting compounds (thermosets) that have been used extensively in pulsed alternator designs. Fillers can be added to tailor properties of the thermoplastic, such as ceramics to increase thermal conductivity at the cost of an increase in density. Thermal analyses have been performed that show the benefits of using thermally conductive potting compounds. In addition, subscale field coil mockups (motorettes) have been encapsulated and tested to demonstrate encapsulation of current field coil geometries.
\end{abstract}

\section{INTRODUCTION}

Current requirements for pulse power alternator designs have dictated the need for continuous discharges over an indefinite period of time, or steady state operations. The primary limiting factor for achieving such a design requirement has been thermal management of losses from ohmic heating and windage. The most direct method of managing such losses is the placement of cooling tubes within the windings of the armature and field coil conductors. Although this method sounds simple and straightforward, additional design issues arise when incorporating cooling tubes inside the field coil conductors. The field coil is typically located in the rotor between composite bandings, spinning at high speeds for maximum energy density. High voltage potentials also develop in the field coil during discharge as the correct amount of amp-turns must be achieved to generate the required magnetic flux. Due to this high 
voltage potential, designs that feature intimate contact between the cooling tubes and the field coil require, as well, insulation breaks within the circuit to isolate the field coil electrically from the shaft and exterior auxiliaries at ground potential. The isolation break would need to withstand the high stresses from rotational loads within the rotor structure and the high internal fluid pressures generated from these same rotational loads.

The additional design complexities created by intimate-contact cooling designs have led to the placement of current field coil cooling systems away from the conductors. The benefits of this design are the freedom to design the cooling path independent of the field coil geometry, and the inherent electrical isolation achieved by the no intimate contact between the cooling tubes and conductors. The problem that remains is sufficiently removing the heat generated from the field coil and windage losses, through the insulation, glass, and graphite materials which generally have low thermal conductivities. In previous designs, the field coil conductors were wrapped with a thin layer of insulation and a thicker layer of glass cloth that was then potted with an epoxy resin through a vacuum-assisted resin transfer mechanism (VARTM) process. In general, the thermal conductivity of such materials is $\sim 0.2$ to $0.3 \mathrm{~W} / \mathrm{m} / \mathrm{k}$. New materials with increased thermal conductivity, but which are still electrically insulative, will improve heat transfer for current field coil cooling designs.

Over recent years, work has been performed in developing thermally conductive thermal plastics for commercial use. Ceramic-filled thermoplastics have been used in spindle motors for disk drives where designs seek to optimize cost, efficiency, and size [1]. The fillers allow physical properties, such as modulus, strain-to-failure, and conductivity, to be tailored to the desired application. These materials have also been used in high strain applications that better reflect the size and load requirements for pulse power generators. The stator windings of a submersible electric motor [2] were encapsulated, which was required to withstand external pressure of 10,000 psi at depths up to $20,000 \mathrm{ft}$.

\section{Thermal PERformance CoMparisons}

Thermal FEA models and simulations have been performed to study the benefits of using thermally conductive thermal plastics for pulse power alternators. One design configuration was analyzed to compare the performance of the traditional epoxy glass system to that of an encapsulated field coil. In this design configuration, the cooling tube assembly was located in a layer below the field coil structure. Thermal loads were generated from windage heating on the outer banding [3] and from field coil losses modeled as repetitive pulse loads. For the first case, the glass epoxy was modeled with a thermal conductivity of $0.3 \mathrm{~W} / \mathrm{m} / \mathrm{k}$, while the second case models a resin formulation produced by LNP Engineering Plastics Inc., Konduit ${ }^{\circledR}$ PDX-STN-01746, which has a conductivity of $1.4 \mathrm{~W} / \mathrm{m} / \mathrm{k}$. From the results shown in Fig. 1, the increased thermal conductivity decreases the temperatures of the field coil and outer banding, which impose limits on operating temperature. The thermoplastic greatly increases the number of discharges allowed before any materials reach maximum operating temperature. 

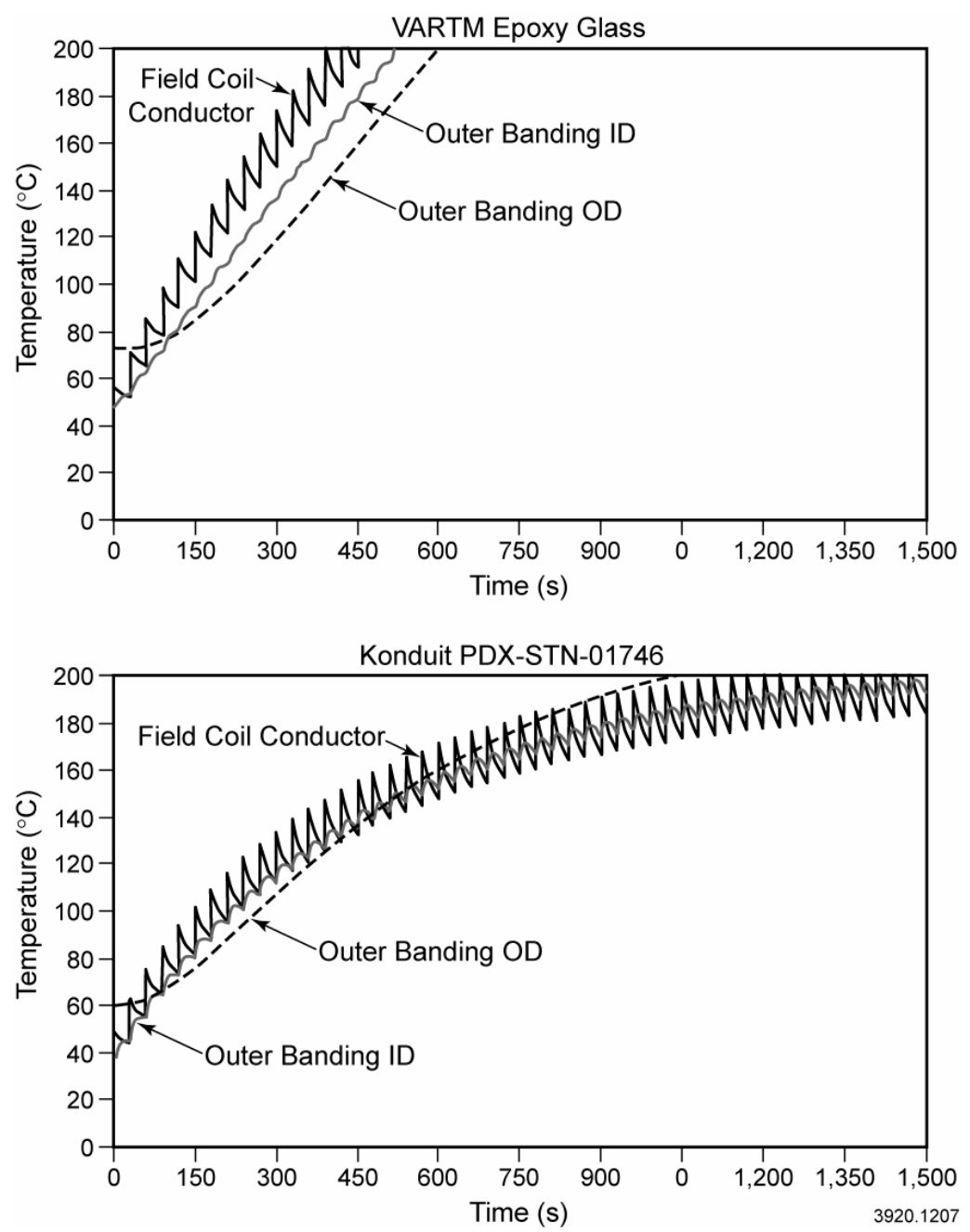

Figure 1. Comparative thermal performance of baseline epoxy glass system (top) vs. thermally conductive thermal plastics (bottom)

\section{Manufacturing Applications}

In addition to the thermal benefits provided by thermally conductive thermal plastics, many manufacturing benefits are also present. The current potting procedures for epoxy glass field coil matrix requires a labor-intensive glass wrapping process of the field coil conductors and an extensive VARTM procedure. To produce a single coil, a minimum of a week of effort is required in setting up the VARTM system, and the process of filling wrapped coil with epoxy can take a day. In contrast, over-molding a structure with thermal plastic takes about a minute. This process can now be industrialized and would allow multiple field coils to be encapsulated in a single day. Injection molding of thermal plastics decreases the chance for formation of voids such as those that develop during a VARTM, due to the high temperatures and pressures the thermoplastic fills the mold. 
The major impediment to developing the technology for injection molding of large field coils is the cost inherent in the mold construction. Large molds are required and must have a sophisticated system of retractable pins, to hold and release the coils during filling, with heated runners to transport the molten thermal plastic through the mold to the cavity. In addition, thermoplastics are inherently more viscous and require significantly higher pressures to fill the molds. Thus a very expensive, high strength mold is required that is capable of sustaining internal pressures in excess of $5 \mathrm{ksi}$. There are only a limited number of injection molding machines in the country with the tonnages required to encapsulate parts the size of a field coil.

In order to prove out the technology and applications to current field coil geometry designs and insulation systems, small flat coil mock-ups (minicoils) were manufactured and encapsulated with various insulation wraps and thermal plastics. The minicoils maintained the same conductor height and spacing as the current field coil designs with an approximated conductor aspect ratio. The goal of these trials was to demonstrate the ability to encapsulate field coil geometries with thermally conductive thermal plastics and to evaluate the compatibility of the primary insulation layers with the process. The thermal plastic enters the mold at $310^{\circ} \mathrm{C}$ and pressures of 35 to 55 MPa (5 to $8 \mathrm{Ksi}$ ). The primary layer of insulation on the field coil conductors must withstand this process.

Nine minicoils were produced for thermoplastic encapsulation trials. Four coils were wrapped with three half-lap wraps of etched Teflon ${ }^{\circledR}$ PTFE, which produces a final insulation build up of $0.3 \mathrm{~mm}$ (12 mils). The next four coils were wrapped with three half-lap wraps of Kapton ${ }^{\circledR} \mathrm{CR}$, which produces an insulation buildup of $0.15 \mathrm{~mm}$ (6 mils). The last coil was first coated with $0.1 \mathrm{~mm}$ (4 mils) of Durafilm ${ }^{\circledR} 300$ polyimide resin, and then over-wrapped with two half-lap wraps of Teflon ${ }^{\circledR}$ for a total insulation buildup of $0.3 \mathrm{~mm}$ (12 mils). Fig. 2 shows a minicoil wrapped with Kapton ${ }^{\circledR}$ CR.

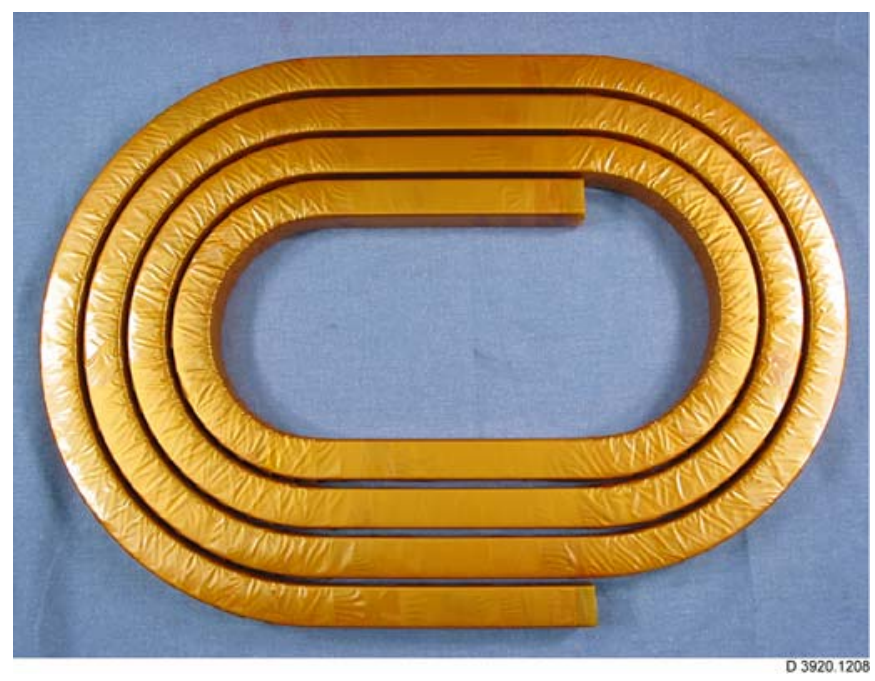

Fig. 2. Flat minicoil wrapped with three half-lap wraps of Kapton ${ }^{\circledR}$ CR film 
The leading candidate material for the thermoplastic encapsulation was a thermally conductive Nylon 4/6 based resin manufactured by LNP plastics, Konduit ${ }^{\circledR}$ PDX-STN-01746. Nylon 4/6 based resins were chosen for their ability to retain properties better at elevated temperature, and this particular resin provided a conductivity of $1.4 \mathrm{~W} / \mathrm{m} / \mathrm{k}$, five times better than current glass epoxy systems. A backup resin was also selected, Konduit ${ }^{\circledR}$ PTF-2155, which is a Nylon 6 based resin with a conductivity of $0.5 \mathrm{~W} / \mathrm{m} / \mathrm{k}$.

At the beginning of the trials, complications developed as the high conductive PDX-STN-01746 resin formulation was implemented. Resin cracks developed during cool down of the molded part. These cracks were attributed to the high filler content that gives the resin high thermal conductivity, but also lowers elongation and makes the resin more brittle. The testing then switched to the backup resin, PTF-2155, which successfully encapsulated the remaining mini-coils. An encapsulated minicoil is shown in Fig. 3.

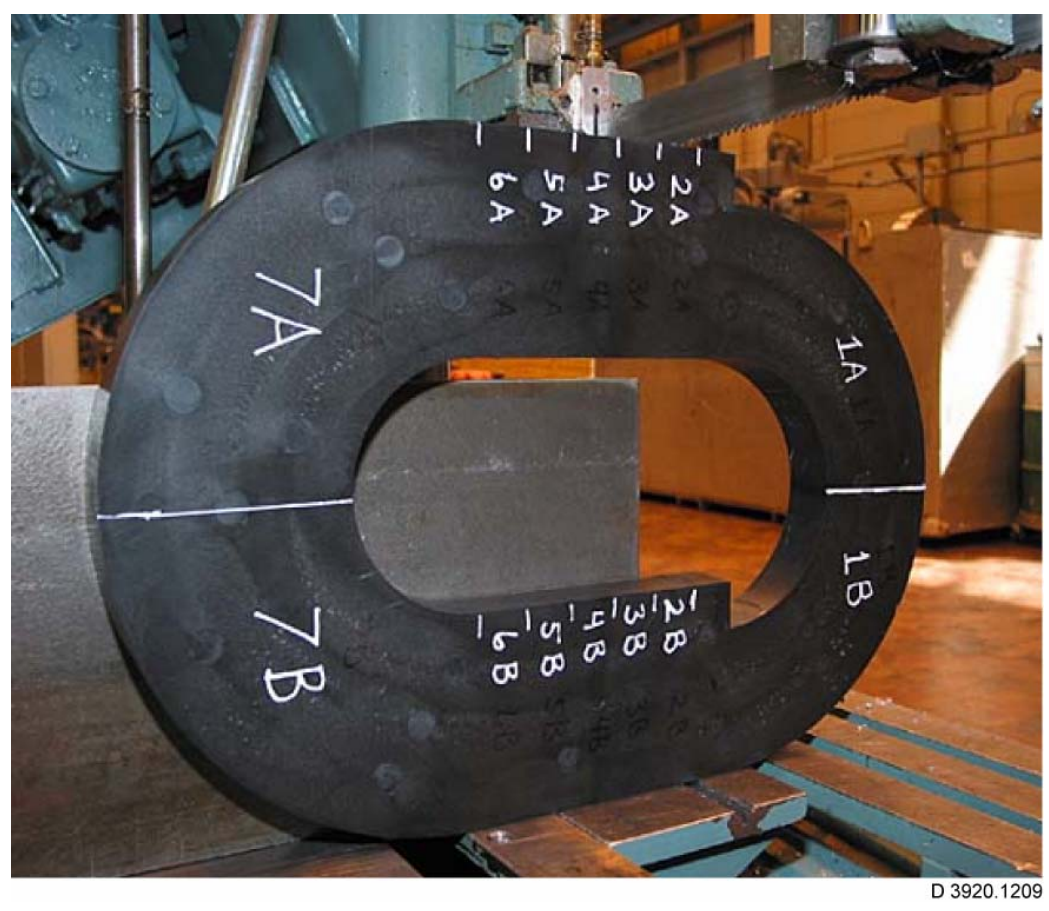

Fig. 3. Encapsulated coil sliced for visual evaluation

The encapsulated coils were evaluated by hi-pot testing and visual inspection of sliced samples under a microscope. Sections of minicoils were sliced and polished to look for voids present in the fill and for visible damage to the field coil insulation. Fig. 4 shows the insulation detailed of a Kapton ${ }^{\circledR}$ CR wrapped coil, and Fig. 5 shows that of a Teflon ${ }^{\circledR}$-wrapped coil. 


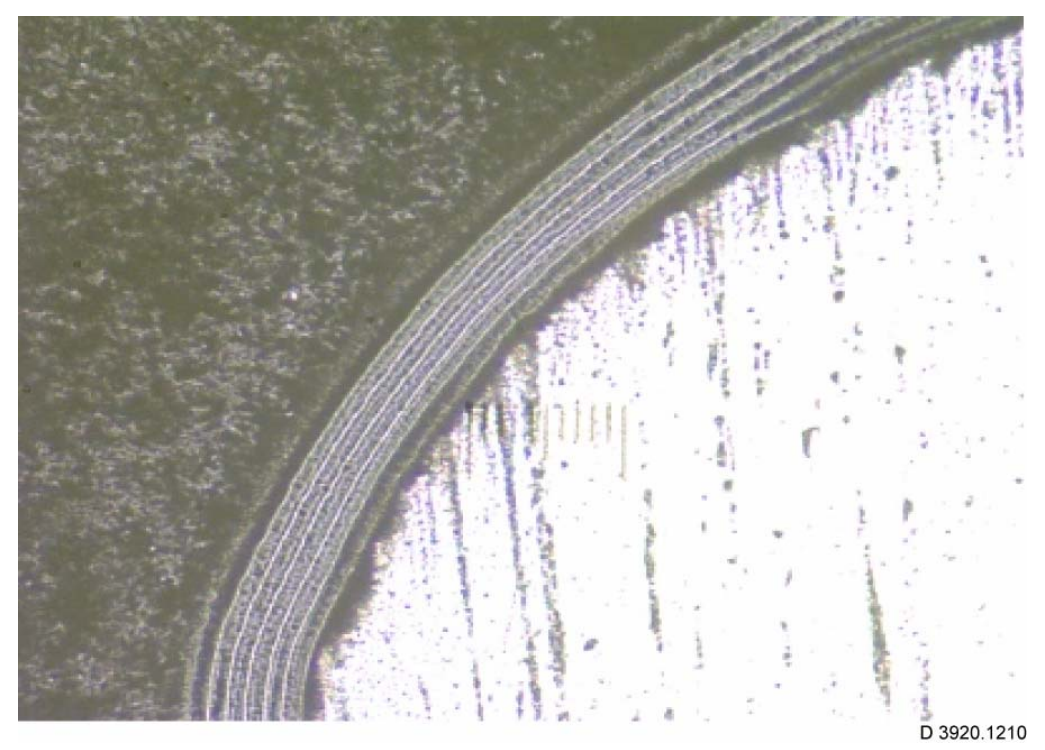

Fig. 4. Kapton ${ }^{\circledR}$ CR layers after injection molding (5X)

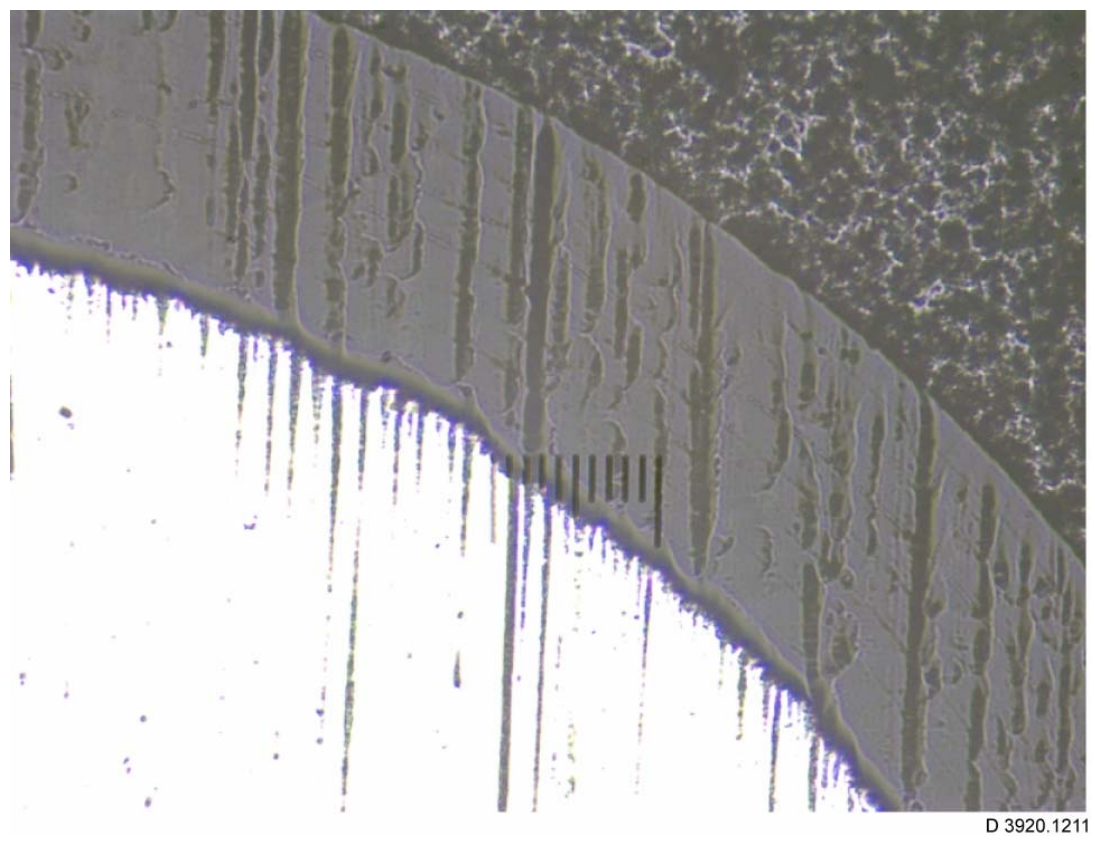

Fig. 5. Teflon ${ }^{\circledR}$ wrapped layers after injection molding (5X)

Visual inspection of sliced coils did not show any evidence of void formation throughout the encapsulant. There also did not appear to be any evidence of damage to the insulation layers, except on some exterior layers of Teflon ${ }^{\circledR}$ film where deformation occurred (Fig. 6). An additional observation was the formation of a boundary layer in the encapsulant filler on the Kapton ${ }^{\circledR}$-wrapped layers that is not present on the Teflon ${ }^{\circledR}$ wrapped layers. A close-up of this layer is shown in Fig. 7. DC hi-potting of the encapsulated mini-coils to a ground plane demonstrated hold-off strengths of 22 to 30 $\mathrm{kV}$, well in excess of designed field coil voltage levels. 


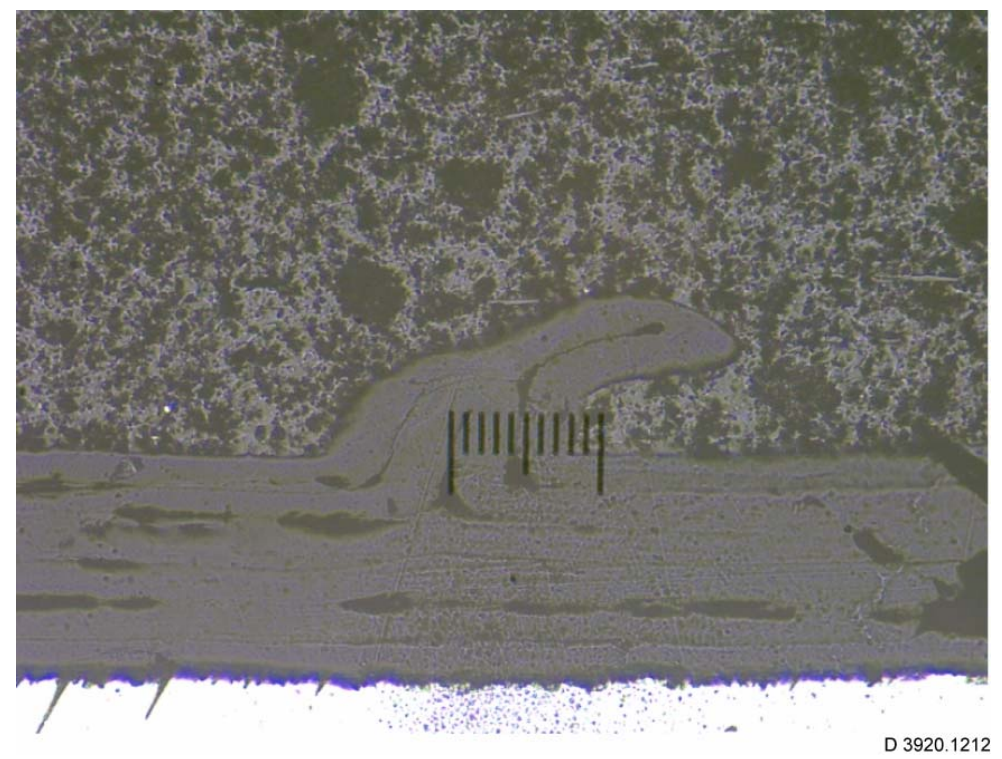

Fig. 6. Deformation of exterior Teflon ${ }^{\circledR}$ layer (5X)

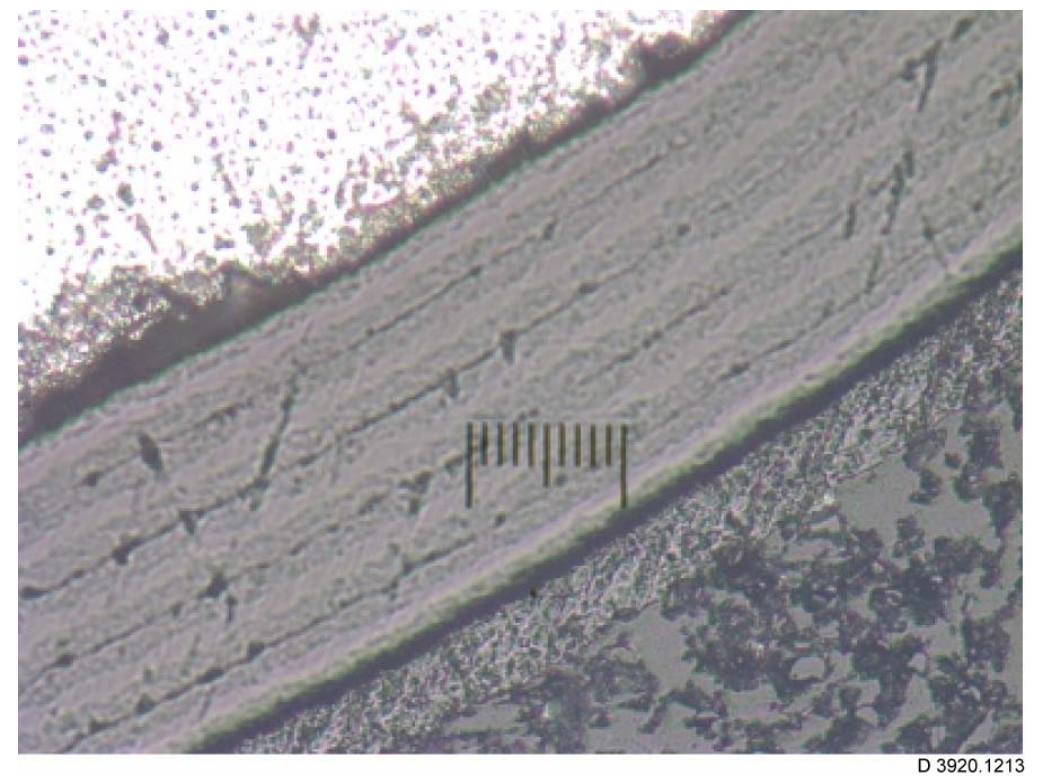

Fig. 7. Close-up of encapsulated Kapton ${ }^{\circledR}$-wrapped conductor; thin boundary layer of nylon appears to have a different grain structure adjacent to Kapton ${ }^{\circledR}$ insulation layers. 


\section{CONCLUSIONS}

Results from thermal analysis show the benefits of using thermally conductive thermoplastics to enhance rotor cooling for pulse power alternators. In addition to thermal performance, it also introduces industrialized manufacturing processes that can greatly reduce time and cost for mass production. More work is needed to determine the achievable limits of resin content and thermal conductivity that can be achieved with conventional thermoplastic injection molding equipment and meet the rigorous pulsed alternator field coil designs.

\section{ACKNOWLEDGMENT}

This work was sponsored by the US Army Research Laboratory through Lockheed-Martin Missile and Fire Control under contract \# 4300050944. The authors would also wish to thank Encap Technologies for expertise on advanced thermoplastic materials and mold design.

\section{REFERENCES}

[1] G.D. Neal, O. Kwon, D.K. Lieu, "Ceramic filled thermoplastic encapsulation as a design feature for a BLDC motor in a disk drive," Encap Technologies Technical Papers, http://www.encaptechnologies.com/papers.html.

[2] "Konduit ${ }^{\circledR}$ thermally conductive composites make revolutionary undersea motors a reality," LNP Engineering Plastics, Inc. press release, June 19, 2000.

[3] H-P. Liu, C.S. Hearn, M.D. Werst, J.J. Hahne, and D. Bogard, "Splits of windage losses in integrated transient rotor and stator thermal analysis of a high speed compulsator during multiple discharges,” IEEE Transactions on Magnetics, vol. 41, no. 1, January 2005, pp. 311-315. 